\title{
Clinical Application of Er:YAG Laser and Cryosurgery in Gingival Depigmentation
}

\author{
${ }^{1}$ Amirhossein Farahmand, ${ }^{2}$ Ahmad Moghareh Abed, ${ }^{3}$ Yasaman Mansouri
}

\begin{abstract}
Background: Gingival melanin pigmentation often occurs as the result of abnormal deposition of melanin. Melanin pigmentation is completely benign and presents no medical problem. However, patients complain the esthetic problem as 'Black Gum'. The aim of this study was to compare the effectiveness of depigmentation by Er:YAG laser and cryosurgery.
\end{abstract}

Materials and methods: This study included 20 patients with gingival pigmentation of maxillary incisors, aged 15 to 44 years. Excluding criteria were smoking, systemic disease and pregnancy. Patients treated randomized split mouth, with Er:YAG laser (Pd: $120 \mathrm{~mJ}, \mathrm{RR}: 12 \mathrm{~Hz}$ ) along with water spraying of half of maxillary gingivae and on the opposite side cryosurgery was done under topical anesthesia. Patients were followed up at 1, 2, 4 weeks and 3, 6, 12 months after treatment.

Results: Healing was uneventful follow-up period for 6 to 12 months showed no repigmentation in none of them. Slight erythema was observed. No postoperative swelling, hemorrhage, pain, infection were reported.

Conclusion: Depigmentation of gingival melanin hyperpigmentation by cryosurgery and Er: YAG laser radiations were found to be an effective procedures. Postoperative patient's satisfaction were impressive.

Keywords: Gingival pigmentation, Er: YAG laser, Cryosurgery.

How to cite this article: Farahmand $A$, Moghareh Abed A, Mansouri Y. Clinical Application of Er: YAG Laser and Cryosurgery in Gingival Depigmentation. World J Dent 2014;5(2):102-108.

Source of support: Nil

Conflict of interest: None

\section{INTRODUCTION}

Pigmentation of the oral mucosa occurs due to wide variety of systemic diseases and conditions. ${ }^{1}$ Physiologic pigmentation is symmetric and persistent and alters normal architecture,

\footnotetext{
${ }^{1}$ Assistant Professor, ${ }^{2}$ Associate Professor, ${ }^{3}$ Dentist

${ }^{1}$ Department of Periodontics, Dental Branch, Islamic Azad University, Tehran, Iran

${ }^{2}$ Department of Periodontics, School of Dentistry, Isfahan University of Medical Sciences, Isfahan, Iran

${ }^{3}$ Private Practice, Iran
}

Corresponding Author: Amirhossein Farahmand, Assistant Professor, Department of Periodontics, Tehran Dental Branch Islamic Azad University, Tehran, Iran, e-mail: perio-implant@ hotmail.com such as gingival stippling (with no age and sex predilection). Often the degree of intraoral pigmentation is not related to the degree of cutaneous and skin color. Pigmentation may be found in any location, but mostly in the gingival area. Physiologic pigmentation occurs due to increased melanin production. ${ }^{2}$ Oral pigmentation is associated to a variety of endogenous and exogenous factors. Most pigmentation is caused by five primary pigments. These include: melanin, melanoid, oxyhemoglobin, reduced hemoglobin, and carotene. While bilirubin and iron can be the cause. ${ }^{3}$ The pigments can be classified from black to light brown. Melanin pigmentation of the gingiva is present in all races.

Although there is equal number of melanin in skin and oral mucosa, they show less activity in the mucosa. Various stimuli's such as trauma, hormonal changes, radiation and medications can result in increased mucosal melanin production. ${ }^{4,5}$ Melanocytes contain tyrosinase, which hydroxylates tyrosine to dihydroxyphenylalanine (dopa). Despite the presence of tyrosinase activity in premelanosome and melanosomes its absent in melanin granules. ${ }^{6}$ Although melanin pigmentation is not usually considered a pathologic lesion, the affected areas can be removed for esthetic reasons. ${ }^{7}$ Recently esthetic demands for a pleasing smile has been increased. Traditionally, gingival depigmentation has been carriedout using nonsurgical and surgical procedures, such as cryosurgery, electrosurgical and laser technique and use of chemical agents. However, those techniques were met with skepticism because of varying degrees of success. ${ }^{8}$ Cryosurgery has been applied for gingival depigmentation using gas expansion system is simple and effective and does not require any sophisticated refined instrument. ${ }^{9,10}$ More recently, lasers (without a specific laser beam) have been used to ablate the epithelial cells including those at basal layer of the affected area. Melanin pigmentations can be removed by using a specific laser wavelength that can be absorbed by pigmented cells without damaging the other cells. However, $\mathrm{CO}_{2}$ and Er: YAG are suitable for nonselective cell ablation. Er: YAG laser produces invisible light with a wavelength of 2,940 nm that has high affinity to water in which it is maximally absorbed which is, similar to the $\mathrm{CO}_{2}$ laser beam. This is due to the water-mediated photothermomechanical process which ablates all living cells within the range of its penetration. ${ }^{11-14}$ 
Recently laser depigmentation has been widely used and is even preferred over surgical technique by many clinicians. The advantages of laser therapy are diminished bleeding, reduced postoperative problems and due to conductibility of irradiant penetration, reduced bone destruction at the treated area. ${ }^{15}$ Studies showed, there is no significant difference in wound healing between various methods. Reports shown wound healing completed by 1 st week using erbium family of lasers whereas complete healing of carbon dioxide laser, argon laser, diode and Nd: YAG can be up to 2 weeks. ${ }^{13,16,17}$

Thermal damage to underlying bone is the side effect of laser (especially Nd: YAG and $\mathrm{CO}_{2}$ lasers) mostly on thin soft tissue during gingivectomy. Tissue penetration from the laser may cause thermal damage 2 to $4 \mathrm{~mm}$ beneath the healthy tissue. ${ }^{16}$ Er: YAG laser radiation energy absorbed in the water is almost entirely converted to water steam, which results in minimal scarring and enables faster wound healing. ${ }^{18-20}$ The Er: YAG laser considered the best choice as it leaves the least thermal damage.

However, there is no scientific evidence to establish that laser depigmentation is superior to surgical depigmentation. ${ }^{21}$ The decision to use a laser should be based on improved hemostasis and less postoperative pain with gingivectomy, frenectomy or other procedures. ${ }^{22}$

\section{MATERIALS AND METHODS}

From the 20 random selected patients whom complained about gingival pigmentation there were 17 females and 3 males, aged 15 to 44 years. The melanin pigmentation was associated with maxillary incisors. Excluding criteria were smoking, systemic disease associated with healing disturbances, pregnancy and postsurgical keloids. Patients were aware that hyperpigmentation had no influence on their oral and systemic health and they have signed a consent form. This study was approved by ethic council of Isfahan University of medical sciences. Three periodontists were participated to evaluate of the rate and score of color density

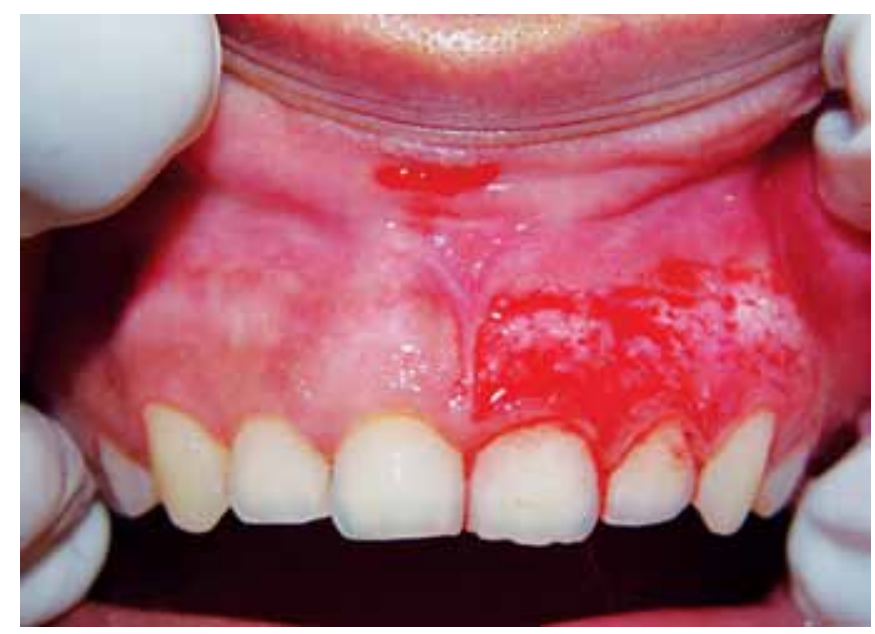

Fig. 1: Postoperative view after Er:YAG laser depigmentation of gingival pigmentations before and after treatments. Color density of gingival pigmentation was assessed using the following criteria: mild (pink-to-slightly brown), moderate (deep brown-to-black), severe (mixed color).

For further evaluation photographs has been taken before and after treatment within the same position and light. The color analysis was done using Adobe Photoshop software with colors of CMYK (Cyan, Magenta, Yellow, Black) and RGB (red, green and blue). The average color has been estimated in each field. Each patient treated with Er: Yag laser (Fotona system made in Slovenia) on one side and on the other side applying cryosurgery. Patients treated with Er: YAG laser. The laser beam used with the following parameters: energy output very long pulse (Pd: $120 \mathrm{~mJ}, \mathrm{RR}: 12 \mathrm{~Hz}$ ), along with water spraying of half of maxillary gingiva, the tip of hand piece placed $2 \mathrm{~mm}$ away from gingival tissue (Fig. 1). The laser output was tested with proper devices. The treatment was performed without topical or local anesthesia. The laser beam was activated using the brush technique. Application period differed according to the degree of melanin pigmentation and epithelial thickness of treated area. Application path was initially delivered along the mucogingival junction, moving toward the free gingival margin. The free gingival margin and papillary gingiva remained untouched to avoid deformity. The cryosurgery was done one the opposite side with cotton swab. The topical anesthesia (2\% lidocaine gel) was applied for 1 to 2 minutes before direct application of $\mathrm{N} 2$ liquid $\left(-196^{\circ} \mathrm{C}\right)$. The swab which had $5 \mathrm{~mm}$ in diameter was gently touch and rolled back and forth on the area for 10 to 15 seconds until disappear area of gingival pigmentation (Fig. 2). All patients were examined at 1,2, 4 weeks, again 3, 6 and 12 months after treatment.

\section{STATISTICS}

The unpaired t-test was used to assess the significant statistical differences between two groups. The paired t-test

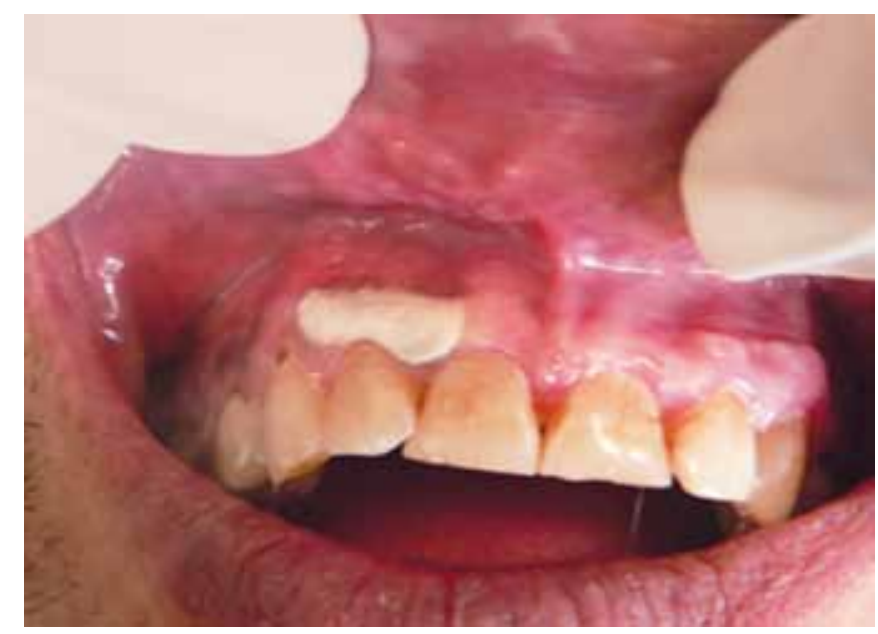

Fig. 2: Postoperative view after cryosurgery depigmentation 
was used to analysis the statistical differences from the initial to 12 month visit within each group. Differences were considered statistically significant $(\mathrm{p} \leq 0.005)$.

\section{RESULTS}

From the 20 patients participated, 4 patient had mild pigmentation and 16 other patients had moderate score. In the following study none of them had any complications such as swelling, hemorrhage, pain, infection, scaring. None of the patients required rest, anti-inflammatory or analgesics drugs. They did not experience any interruption in performing normal daily activities. Healing was eventful, the patient's approval of the procedure was good, and the results were excellent.

However, at sites where melanin pigmentation removal required deeper lasing and freezing, bleeding was evident. Irrigation helped reducing the burning smell during the procedure. After 24 hours the lased and freezed gingiva was covered with thin layer of whitish-yellowish exudates, which exfoliated during the first week following treatment. Re-epithelization was observed during 1 to 2 weeks.

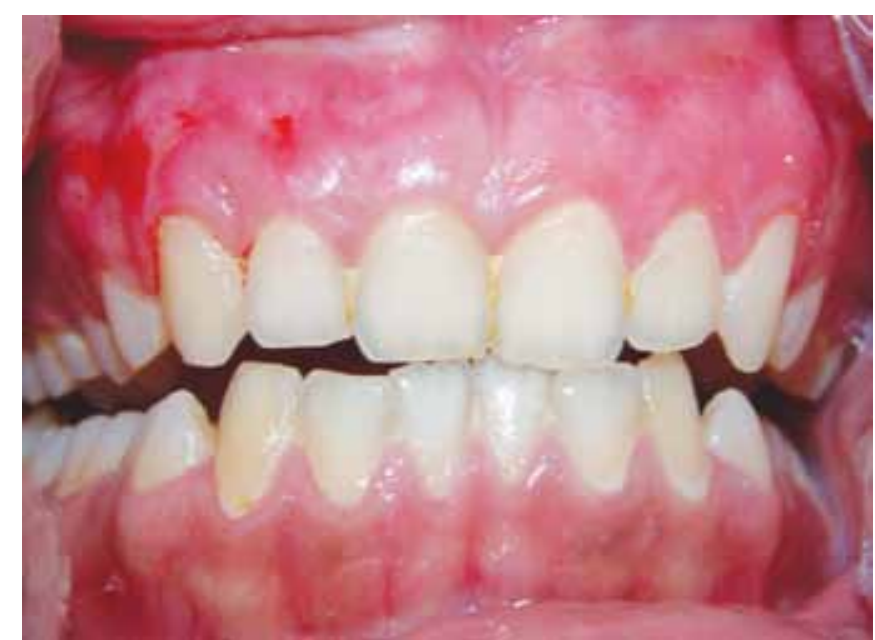

Fig. 3: (Right side) one week after cryosurgery, (Left side) two weeks postoperative laser application

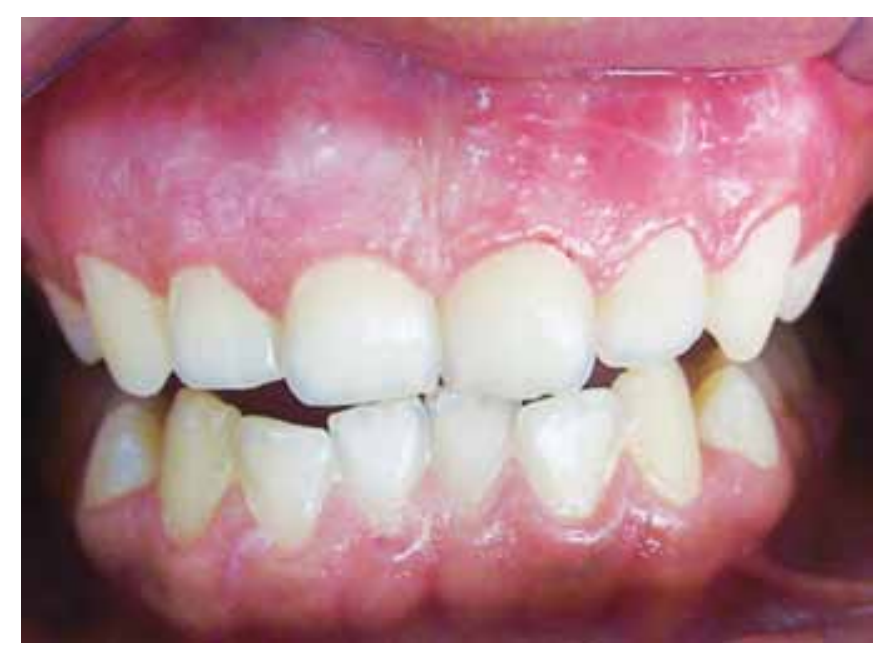

Fig. 5: Six months postoperative gingival depigmentation
Keratinization was appeared in 3 to 4 weeks after the treatment. Slight erythema was evident at the operated area (Fig. 3). During 6 to 12 months follow-up, no signs of recurrence were observed (Figs 4 to 6). Gingival recession did not occur at the operated sites. Photographic analysis were performed by both CMYK and RGB (Adobe Photoshop color scaling system). Collected data were analyzed using paired test and t-test before and after treatment. Comparing the results after 12 months with preoperated pictures has shown significant changes $(p \leq 0.005)$ (see Figs 1 and 2$)$. There was no significant difference $(p \geq 0.005)$ of RGB and CMYK systems in both methods (Tables 1 and 2). However, there was a significant difference $(\mathrm{p}<0.005)$ in red coloring (Graphs 1 and 2). The patients evaluated by three periodontists none of them could recognize the method used in treated area.

\section{DISCUSSION}

Melanin pigmentation is a common physiologic phenomenon in all races ${ }^{23}$ However, the pigmentation is determined by melanocytes level of activity rather than their density in the

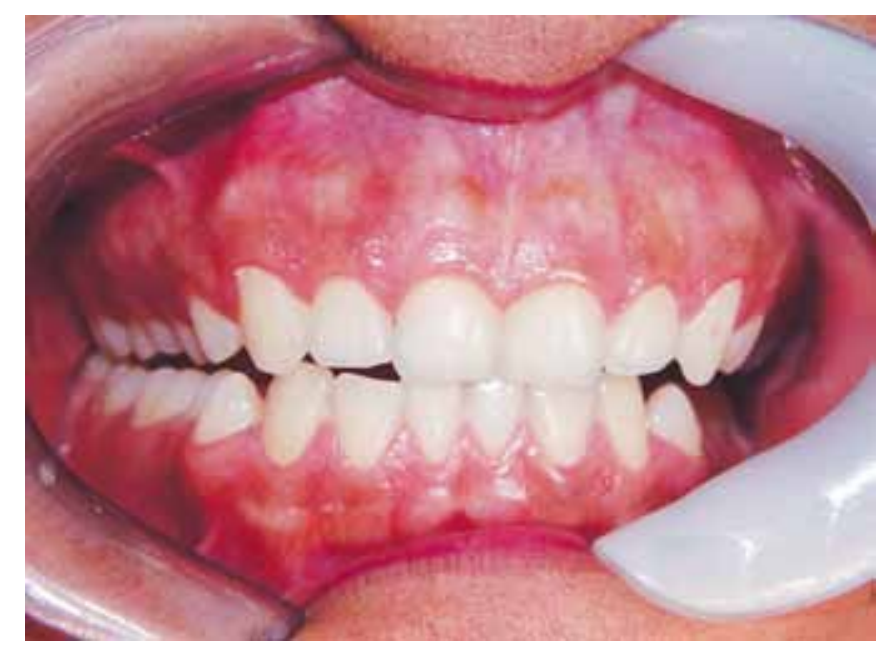

Fig. 4: Preoperative area of gingival pigmentation

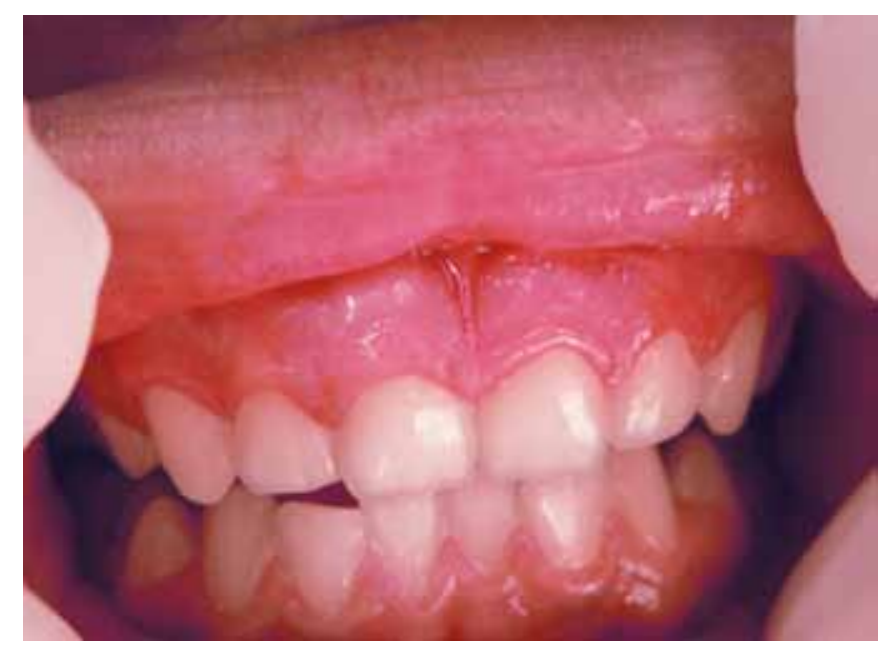

Fig. 6: One year after depigmentation 


Table 1: Mean of RGB color value (software scale) compared
before and after laser therapy

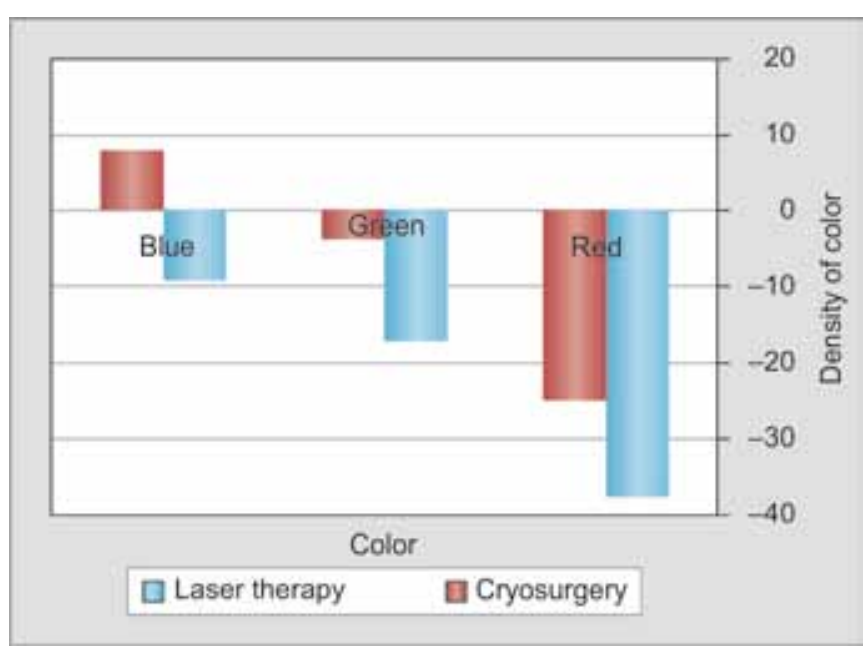

Graph 1: Mean of gingival brightness by RGB application before and after treatments

epithelial basal-cell layer. ${ }^{24}$ Within individuals, melanocyte activity may vary in different locations of gingival tissue leading to the variable pattern of pigmentation commonly seen in gingival pigmentation. ${ }^{6-25}$

Hirschfelds in (1951) used phenol (90\%) and alcohol (95\%) to remove pigmented areas to destroy tissue slightly below the basal layer of mucous membranes. However, repigmentation soon occurred in 3 out of 20 patients, the rest had the same results shortly later. ${ }^{26}$

Dummet et al (1963) reported repigmentation after gingivectomy observed in $67 \%$ of the areas, as early as 33 days after surgical removal and, repigmentation did not occur in the rest of the cases up to 431 days after surgery. ${ }^{7}$

In 1990, Farnoosh described, depigmentation of gingiva with a high-speed hand piece and diamond bur with water lavage for esthetic purposes and after 18 months follow-up, none of the cases showed any recurrence of the pigmentation. ${ }^{27}$ Mokeem applied the surgical abrasion technique for gingival hyperpigmentation with a high-speed hand piece and diamond bur with copious water lavage. ${ }^{28}$ Perlmutter et al reported the removal of the pigmented area via through the elevations of partial-thickness flaps although the results were satisfactory for 2 years postoperatively, repigmentation occurred after this period. ${ }^{25}$

Tamizi et al replaced pigmented gingiva with unpigmented free gingival graft autografts in 10 patients. At
Table 2: Mean of RGB color value (software scale) compared before and after cryosurgery

\begin{tabular}{llll}
\hline Color type & $\begin{array}{l}\text { Before treatment } \\
\text { Color value } \\
\text { (mean } \pm S D)\end{array}$ & $\begin{array}{l}\text { After treatment } \\
\text { Color value } \\
\text { (mean } \pm S D)\end{array}$ & $p$-value \\
\hline $\mathrm{R}$ & $160.8 \pm 28$ & $185.85 \pm 16.2$ & 0.002 \\
$\mathrm{G}$ & $82.95 \pm 22.7$ & $86.80 \pm 36.62$ & 0.666 \\
$\mathrm{~B}$ & $79.05 \pm 39.7$ & $71 \pm 39.37$ & 0.493 \\
\hline
\end{tabular}

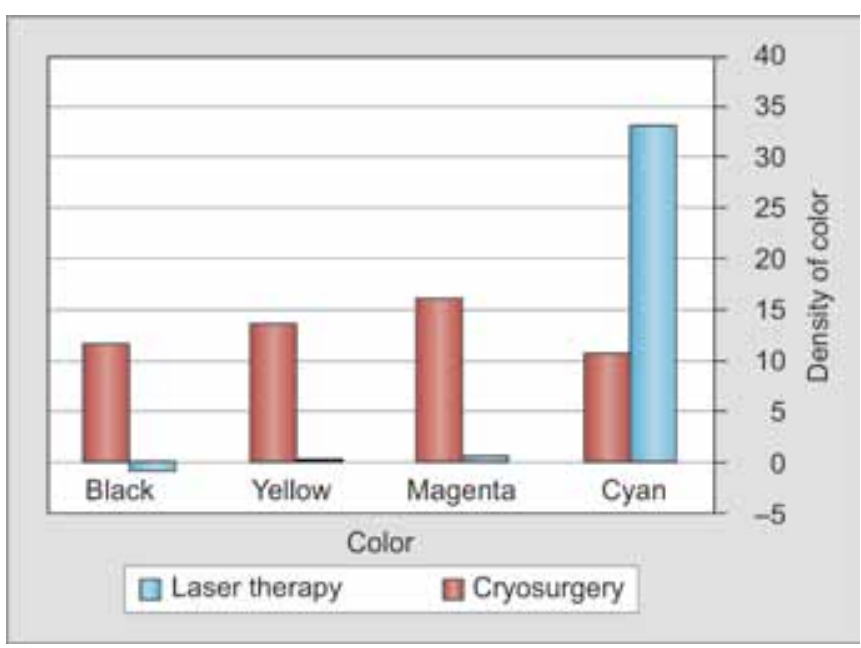

Graph 2: Mean of gingival brightness by CMYK application before and after treatments

least two areas in each patient were grafted; one with a full-thickness flap and the other with a partial-thickness flap. No evidence of repigmentation was found during 4.5 years, only one case of recurrence was observed after 1 year in a patient treated with a partial-thickness flap. Although the results were favorable, this technique required the use of an additional surgical area, and healing was slow and painful. There was limited amount of tissue available in donor area and the esthetic result was not always satisfactory due to color differences between the two areas. ${ }^{29}$

Arikan et al in 2007, administered tetrafluoroethane-cooled cotton swab. Keratinization was completed 3 to 4 weeks after application, without any trace of pigmentation and the esthetics were maintained up to month. ${ }^{30}$

In1993, Bergamaschi studied melanin repigmentation after gingivectomy. Two of five patient reached baseline coloration 1.5 years post-surgery, while the rest returned to baseline coloration by 3 years post-surgery. ${ }^{31}$

Grover et al in 2010, de-epithelialized the gingiva using high-speed hand piece and diamond bur with copious water lavage. Removal of gingival melanin pigmentation should be performed cautiously since inappropriate application may cause gingival recession, damage to the underlying periosteum and bone, delayed wound healing, as well as loss of enamel. Gingival abrasion using a round bur is a comparatively simple, safe and nonaggressive method that is both easily used and 
readily repeated, if necessary, to eradicate any residual or repigmented area. ${ }^{32}$

The effectiveness of melanin hyperpigmentation removal with different types of lasers has been evaluated in several studies. The use of pulsed erbium- doped: yttrium, aluminum, and garnet (Er:YAG) lasers has gained increasing importance and acceptance in recent years. ${ }^{9}, 11-13,17$

The Er: YAG laser was chosen in this study due to wellabsorption by tissue water molecules. The possibility to ablate the epithelium in a nonselective manner results in less thermal diffusion, coagulative necrosis and collagen shrinkage in comparison to other lasers and does not form hemostasis. ${ }^{14,19,20}$ These observations are valid, especially as Er: YAG is compared with the $\mathrm{CO}_{2}$ lasers, which is commonly used in the dental office. ${ }^{21}$

The brush technique, with a defocused beam seems to be safe and effective. Atsawasuwan used the same technique with Nd: YAG laser and there was no recurrence after 11 to 13 months of follow-up. However, in delicate areas such as the marginal gingiva, the Nd: YAG laser should be used cautiously. ${ }^{13}$ Kesler et al reported, with laser energy density of $1 \mathrm{~J}$, one to four passes would be sufficient for complete removal of the epithelium and there was no scarring or gingival infection..$^{8-14}$ Tal et al used energy per pulse of $500 \mathrm{~mJ}$ for depigmentation by Er: YAG laser and reported treatment was safe, with pleasing esthetic results, healing was uneventful. ${ }^{7}$ Kawashima used irradiation at 27 to $54 \mathrm{~mJ} /$ pulse and 20 to $30 \mathrm{~Hz}$ under water spray in an oblique contact mode with the participation of five patients. The clinical parameters were evaluated after 6 months. There were no prominent bleeding complications. Within 2 weeks, the gingiva appeared completely normal. In some cases, slight recurrence was observed after 6 months. ${ }^{33}$ These results are in agreement with the present clinical observations.

In the present study, topical anesthetic was not administered with repeated solutions. Atsawasuwan et al administered local anesthesia, but in their patients, although ablation was deeper, no repeated topical anesthesia was used. There were no complaints of pain during treatment; none described it as uncomfortable or requiring supportive therapy. ${ }^{13}$ In a study done by Azzeh, all patients reported absence of pain intraoperatively (without the use of topical or local anesthesia), immediately postoperatively, and after 4 days. ${ }^{34}$ However, Tal et al used erbium:YAG laser and applied topical anesthesia repeatedly, and three patients used mild analgesics. ${ }^{7}$ Pain reduction after using lasers may be in irradiated tissue, which have sterilization effects, stimulate fibroblasts, and cause collagen and extracellular matrix formation. All of these factors may explain rapid wound healing after using an Er: YAG laser. Because the Er: YAG laser has the least thermal damage. ${ }^{28}$
In Aoki et al study, sixty-one patients were subjected to gingivectomy, removal of gingival melanin pigmentation, or frenectomy with using the Er: YAG laser. Clinical parameters were evaluated before, immediately after, and at 1 and 4 weeks after surgery. The Er: YAG laser was capable of cutting or ablating gingival soft tissue easily and effectively with less or no bleeding as well as less pain. The healing process was uneventful without any complications or side effects. The results of this study suggest that the Er: YAG laser at $30 \mathrm{~Hz}$ could be used safely and effectively for minor periodontal soft tissue management without causing major thermal damage as well as the delay of wound healing. ${ }^{35}$

In 1999 Nakamura described repigmentation only in four of seven patients at 24 months, after using $\mathrm{CO}_{2}$ laser on the removal of gingival melanin pigmentation. It has been claimed that following laser ablation of hyperpigmented areas, the gingival heal uneventfully and that usually the gingiva completely regenerates, appears healthy, pink and firm. These observations are commonly shared between clinical researchers, who used different lasers and various techniques. ${ }^{36}$ Sharon et al 2000 applied of $\mathrm{CO}_{2}$ laser in ablating gingival and cutaneous melanin in dogs and reported no recurrence of gingival pigmentation, however, a small amount of repigmentation was noticeable in the skin. ${ }^{12}$ Esen et al treated 10 patients with super pulsed $\mathrm{CO}_{2}$ laser. gingival. Ablation of the hyperpigmented gingiva was accomplished with minimal carbonization and almost no bleeding. During 24 months of follow-up two cases shown partial repigmentation. ${ }^{37}$ Şimşek Kaya et al 2011, in their study used a gallium aluminum arsenide diode laser with a continuous wavelength of $808 \mathrm{~nm}$ in one group (10 patients), and another group (10 patients) with an Er: YAG laser with a continuous wavelength of $2,940 \mathrm{~nm}$. Gingival depigmentation was performed by applying the laser at $1 \mathrm{~W}$. There was no occurrence of unpleasant events during the actual procedure or the healing period. The total length of treatment was significantly shorter with the diode laser than with the Er:YAG laser. No melanin recurrence was detected during any follow-up session. ${ }^{38}$ Moghareh Abed et al considered and used the cryosurgery to treat gingival pigmentation in 20 patients. The RGB, CMYK color analysis of Adobe Photoshop software used. Results have shown that treated area was 40 to $50 \%$ of cases color of gingival was bright than control group. ${ }^{39}$ Tal used a cryosurgical technique to remove gingival melanin pigmentations, with satisfactory results over 20 months postoperatively. ${ }^{9}$

Yeh performed cryosurgeries using liquid nitrogen and the gingiva became depigmented after one or two sessions. Although this technique appears efficacious, it requires specific equipment that makes it more expensive. ${ }^{10}$ Yeh described that after cryosurgery, no postoperative pain, 
hemorrhage, infection or scarring occurred in any of the patients. Healing was uneventful, patient acceptance of procedure was good; the results were excellent. ${ }^{40}$

In this study, there was no recurrence in the period of 12 months, which can be predictive in the future. Laser and cryosurgery have the following advantages: less hemorrhage, easy technique with shorter duration of treatment, minimal side effects. Moreover, as laser irradiation is applied in a noncontact manner, therefore reduces the possibility of infection. Therefore, laser irradiation could be considered superior to conventional surgical techniques.

\section{CONCLUSION}

Depigmentation of gingival melanin hyperpigmentation by cryosurgery and Er: YAG laser radiation were found to be an effective procedures. Postoperative patients satisfaction were impressive. There was no recurrence after 12 months follow-up.

\section{REFERENCES}

1. Meyerson MA, Cohen PR, Hymes SR. Lingual hyperpigmentation associated with minocycline therapy. Oral Surg Oral Med Oral Pathol Oral Radiol Endod 1995;79:180-184.

2. Regezi JA, Sciubba JJ. Jordan RCK, editors. Oral Pathology: Clinical Pathologic Correlations. 4th ed. St. Louis: Saunders: 2003:129-142.

3. Steigmann S. Treatment of melanin-pigmented gingiva and oral mucosa by $\mathrm{CO}_{2}$ laser. Oral Surg Oral Med Oral Pathol Oral Radiol Endod 2000;90:14-15.

4. Gorsky M, Buchner A, Fundoianu-Dayan D, Aviv I. Physiologic pigmentation of the gingiva in Israeli Jews of different ethnic origin. Oral Surg Oral Med Oral Pathol 1984;58:506-509.

5. Amir E, Gorsky M, Buchner A, Sarnat H, Gat H. Physiologic pigmentation of the oral mucosa in Israeli children. Oral Surg Oral Med Oral Pathol 1991;71:396-398.

6. Dummet CO, Barens G. Oromucosal pigmentation: an updated literary review. J Periodontol 1971;42:726-736.

7. Tal H, Osgiesser D, Tal M. Gingival pigmentation by ER: YAG: clinical observation and patient responses. J Peridontal 2003; 74:1660-1667.

8. Joseph P, David M. Clinical features of gingivitis In: Newman et al. Carranza's Clinical Periodontology. WB Saunders, Philadelphia, 2000;p. 366-367.

9. Tal H, Landsburg J, Kozlovsky A. Cryosurgical depigmentation of the gingival. J Clin Periodontal 1987;57:48-50.

10. Yeh CJ. Cryosurgical treatment of melanin-pigmented gingival. J Oral Surgery Oral med Oral Pathol 1988;86:660-662.

11. Ozbayrak S, Dumlu A, Ercalik-Yalcinkaya S. Treatment of melanin-pigmented gingiva and oral mucosa by $\mathrm{CO}_{2}$ laser. Oral Surg Oral Med Oral Pathol Oral Radiol Endod 2000;90:14-15.

12. Sharon E, Azaz B, Ulmansky M. Vaporization of melanin in oral tissues, skin with $\mathrm{CO}_{2}$ laser: a canine study. J Oral Maxillofac Sur 2000;58:1387-1393.

13. Atsawauwan P, Greethong K, Nimmanon V. Treatment of gingival hyperpigmentation for esthetic purposes by Nd: YAG laser; report of 4 cases. J Periodontol 2000;71:315-321.
14. Kesler G, Koren R, Kesler A, Kristt D, Gal R. Differences in histochemical characteristics of gingival collagen after Er: YAG laser periodontal plastic surgery. J Clin Laser Med Surg 2000; 18:203-207.

15. Pick RM, Pecaro BC, Silberman CJ. The laser gingivectomy: the use of the $\mathrm{CO}_{2}$ laser for the removal of phenytoin hyperplasia. J Periodontol 1985;56:492-496.

16. Berk G. Treatment of gingival pigmentation wit Er, Cr: YSGG laser. J Oral Laser Applications 2005;5(4):249-253.

17. Rizoiu IM. Effects of an erbium, chromium: yttrium, scandium, gallium, garnet laser on mucocutaneous soft tissue. Oral Surg Oral Med Oral Pathol Oral Radiol Endod 1996;82(4):386-395.

18. Spencer P, Cobb CM, Wieliczka DM, Glaros AG, Morris PJ. Change in temperature of subjacent bone during soft tissue laser ablation. J Periodontol 1998;69:1278-1282.

19. Walsh JT, Flotte TJ, Deutsch TF. Er: YAG laser ablation of tissue: effect of pulse duration and tissue type on thermal damage. Laser Surg Med 1989;9:314-326.

20. Walsh JT, Deutsch TF. Er:YAG laser ablation of tissue: Measurment of ablation rates. Laser Surg Med 1989;9:327-330.

21. Alster TS, Nanni CA, Williams CM. Comparison of four carbon dioxide lasers: clinical and histopathologic evaluation. Dermatol Surg 1999;25:1-4.

22. Berger JW, D'Amico DJ. Modeling of erbium:YAG laser mediated explosive photovaporization: Implications for vitreoretinal surgery. Ophthalmic Surg Laser 1997;28:133-139.

23. Roshna T, Nandakumar K. Anterior esthetic gingival depigmentation and crown lengthening: report of a case. J Contemp Dent Pract 2005;6:139-147.

24. Mobio S, Noujeim Z, Boutigny H, Jensen M, Cassia A, Soueidan A. Pigmentation and pigmented lesions of the gingival mucosa. Rev Belge Med Dent 2008;63:15-28.

25. Perlmutter $\mathrm{S}$, Tal $\mathrm{H}$. Repigmentation of the gingiva following surgical injury. J Periodontol 1986;57:48-50.

26. Hirschfeld I, Hirschfeld L. Oral pigmentation and method of removing it. Oral Surg Oral Med Oral Pathol 1951;4:1012-1016.

27. Farnoosh A. Treatment of melanin pigmentation and discoloration for esthetic purposes. J Periodont Restor Dent 1991; 10:313-318.

28. Sameer A. Mokeem, management of gingival hyperpigmentation by surgical abrasion. Report of three cases. Saudi Dental J 2006;18(3):162-165.

29. Tamizi M, Taheri M. Treatment of severe physiologic gingival pigmentation with free gingival autograft. Quintessence Int 1996; 27:555-558.

30. Arikan F, Gürkan A. Cryosurgical treatment of gingival melanin pigmentation with tetrafluoroethylene. Oral Surg Oral Med Oral Pathol Oral Radiol Endod 2007;103:452-457.

31. Bergamaschi O, Kon S, Doine AI, Ruben MP. Melanin repigmentation after gingivectomy: a 5-year clinical and transmission electron microscopic study in humans. Int J Periodon Restor Dent 1993;13:85-92.

32. Grover S. Shukla P, Malhotra G, Saraswat S. Depigmentation by surgical abrasion: a case report. JIDA 2010;12(4):132-136.

33. Kawashima Y, Aoki A, Ishii S, Watanabe H, Ishikawa I. Laser treatment of gingival melanin pigmentation. Inter Congress Series 2003;1248:245-248.

34. Azzeh MM. Treatment of gingival hyperpigmentation by erbiumdoped: yttrium, aluminum, and garnet laser for esthetic purposes. J Periodontol 2007 Jan;78(1):177-184. 
35. Aoki A, Watanabe H, Namiki N, Takiguchi T, Miyazawa Y, Suzuki M, Hasegawa K, Ishikawa I. Periodontal soft tissue management with a high pulse rate Er: YAG laser. Inter congress series 2003;1248:367-369.

36. Nakamura Y, Hossain M, Hirayama K, Matsumoto KA. A clinical study on the removal of gingival melanin pigmentation with the $\mathrm{CO}_{2}$ laser. Lasers Surg Med 1999;25:140-147.

37. Esen E, Haytac MC, Oz IA, Erdogan O, Karsli E. Gingival melanin pigmentation and its treatment with the $\mathrm{CO}_{2}$ laser. Oral Surg Oral Med Oral Pathol Oral Radiol Endod 2004;98:522-527.
38. Kaya GS. Yavuz GY. Sümbüllü MA, Day EA. comparison of diode laser and Er: YAG lasers in the treatment of gingival melanin pigmentation. Oral Surg Oral Med Oral Pathol Oral Radiol 2012 Mar;113(3):293-299.

39. Abed MA, Rabiee F. Evaluation of the treatment for gingival pigmentation by cryotherapy (N2 liquid). Shahid Beheshti Univ Dent J 2006;23:656-662.

40. Yeh CJ. Simple cryosurgical treatment of the oral melanotic macule. Oral Surg Oral Med Oral Pathol Oral Radiol Endod 2000;90:12-13. 